\title{
Familial Parkinson's Disease: Possible Role of Environmental Factors
}

\author{
Susan Calne, Bruce Schoenberg, Wayne Martin, \\ Ryan J. Uitti, Peter Spencer, D.B. Calne
}

\begin{abstract}
We report here six families with Parkinson's disease in whom the onset of symptoms tended to occur at approximately the same time irrespective of the age of the patient. The mean difference in the time of onset in different generations was 4.6 years while the mean difference in age of onset in children and parents was 25.2 years. We construe this pattern of age separation within families as suggestive of an environmental rather than genetic cause. Support for this view derives from the lack of correlation between occurrence of the disease and the degree of consanguinity. We conclude that our findings are in accord with the hypothesis which attributes the cause of some cases of Parkinson's disease to early, subclinical environmental damage followed by age-related attrition of neurons within the central nervous system.
\end{abstract}

\begin{abstract}
RÉSUMÉ: La maladie de Parkinson familiale est compatible avec l'hypothèse d'une étiologie environnementale. Nous décrivons 6 familles atteintes de la maladie de Parkinson dont le début de la symptomatologie est apparu à peu près au même moment, indépendamment de l'âge du patient. La différence moyenne dans le temps d'apparition dans des générations différentes était de 4.6 ans, alors que la différence moyenne entre l'âge d'apparition chez les enfants et chez les parents était de 25.2 ans. Nous interprétons ce mode de séparation de l'âge de début à l'intérieur des familles comme étant compatible avec une cause environnementale plutôt qu'avec une cause génétique de la maladie. Cette opinion est appuyée par l'absence de corrélation entre l'apparition de la maladie et le degré de consanguinité. Nous concluons que nos observations sont conformes à l'hypothèse selon laquelle la cause de certains cas de la maladie de Parkinson serait une insulte environnemental précoce, subclinique, suivie d'une perte progressive de neurones dans le système nerveux central, due au vieillissement.
\end{abstract}

Can. J. Neurol. Sci. 1987; 14:303-305

It has previously been argued that in certain instances degenerative disease localized to specific regions of the central nervous system in the elderly might derive from a combination of early environmental subclinical damage and gradual, selective, age-related attrition of certain neuronal populations. ' Environmental exposures common to an isolated human group such as members of a family living together, may thus lead years or decades later to the simultaneous appearance of disease in exposed subjects. Familial aggregations have been reported for Parkinson's disease so it is logical to ask whether such familial clusters represent genetic predisposition, common exposure to an environmental factor(s), or both.

The focus of previous reports on familial Parkinson's disease has been genetic analysis. While we do not deny the existence of an hereditary component, we present here evidence that implicates an environmental origin for at least some of the familial patterns. This thesis is based upon our own case reports. The implications of our argument also support the general hypothesis that some neurodegenerative disorders of the elderly are of environmental origin and that a latent period of many years intercedes between subclinical damage and the emergence of clinical features.

Our view is predicated upon several premises relevant to the task of distinguishing between environmental and genetic causation of disease:

(1) The age of onset of clinical symptoms is a crucial factor. Non-familial Parkinson's disease generally starts between the ages of 50 and 70 years. If a familial disorder has an environmental aetiology consequent upon exposure to a causal agent over a limited period of time, the appearance of clinical disease should be aggregated chronologically in all affected relatives, irrespective of their age at the time of onset. There will be a similar time of onset rather than a similar age of onset. Conversely, genetic disease would be expected to present in the same age range in all generations, and this would naturally mean onset at different times.

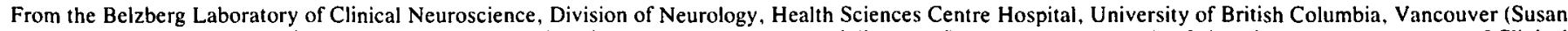

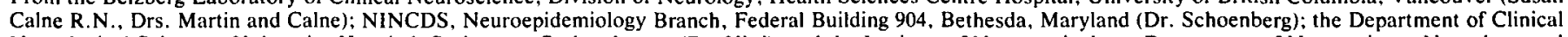

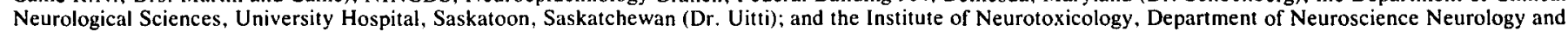
Pathology, Albert Einstein College of Medicine Bronx, New York (Dr. Spencer)

Received March 24, 1987. Accepted May 30, 1987

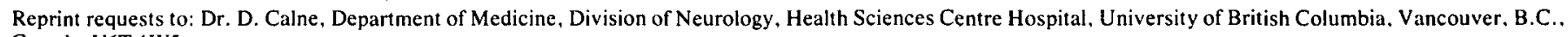
Canada V6T IW5 
Some flexibility exists in the interpretation of findings to take account of such possibilities as increased vulnerability to environmental damage in late life (because of a dwindling neuronal reserve and decreased immunological or metabolic protective capacity). The 'dose' of environmental insult may also influence the outcome; a higher level of exposure to a culpable environmental agent in one group of subjects may lead to earlier emergence of symptoms and hence disturb the tendency for all affected individuals to present with clinical disease simultaneously.

(2) For genetic disease the concordance rate will correlate with the degree of consanguinity. It will be higher in monozygotic twins than dizygotic twins, and there will be no risk in relatives by marriage, unless they happen to be cousins.

\section{Patients}

In the context of the above arguments, we present a number of our own patients whose case histories conform to the pattern expected for environmental causation, deriving from 6 families with Parkinson's disease. Affected family members all had onset of clinical symptoms at approximately the same time, with age differences at the time of onset averaging 25.2 years between child and parent. Familial cases in which the time of onset of clinical symptoms between generations or siblings was greater than 10 years were excluded. In one of the Parkinsonian families, the parents (unrelated to each other) both developed symptoms at approximately the same time as their son. Parkinson's disease was also found in one non-twin sibling of a pair of monozygotic twins one of whom was affected; the mean difference in age of onset in these siblings was one year. One subject with an unaffected monozygotic twin, had an affected parent. These findings are summarized in Table 1. All subjects have been examined by a neurologist with an extensive experience in movement disorders. We have employed the criteria for diagnosing Parkinson's disease published by Schoenberg et al. ${ }^{2}$ The rate of progress of illness varied, but all these fell within the range normally seen in this disorder. In the following case reports, we have added comments on any unusual environmental feature that we could identify.

Table 1: Date and age of onset in families with Parkinson's disease

\begin{tabular}{crrrrr}
\hline \hline \multicolumn{4}{c}{ Age of Patients and Years } & at Onset of Symptoms(years) & Time Interval \\
Family & \multicolumn{1}{c}{ Child } & Sibling & Father & Mother & in Relatives \\
\hline 1 & $+37(1963)$ & & $68(1964)$ & $58(1961)$ & 2 (Mean) \\
2 & $+33(1986)$ & & & $54(1981)$ & 5 \\
3 & $57(1986)$ & & & $+78(1984)$ & 2 \\
4 & $+30(1974)$ & & $61(1980)$ & 6 \\
5 & $+42^{*}(1965)$ & $62(1957)$ & & 8 \\
6 & $+54^{*}(1974)$ & $51(1975)$ & & & 1 \\
\hline
\end{tabular}

+ Index Case

* Having an unaffected monzygotic twin.

Mean age of onset in children $=39.8$ Range 30-57

Mean age of onset in parents $=63.6$ Range 54-78

Mean difference in age of onset between generations $=25.2$ Range 20-31

Mean difference in age between generations $=25.6$ Range 23-30

Mean time difference between onset in generations $=4.6$ Range 8-2

Mean difference in age of onset between siblings $=1$ year

Mean difference in age between siblings $=4$ years

Mean age of mothers at birth of child $=23$ Range 18-30

Mean age of fathers at birth of child $=29$ Range 28-30

\section{CASE REPORTS}

\section{Family 1}

The index case (male) developed tremor, rigidity and masking of facial expression in 1963 at age 37 years when Parkinson's disease was diagnosed. His mother's illness began in a similar way in 1961 and she was diagnosed as having Parkinson's disease at age 58 years. The father was also reported to have suffered from Parkinson's disease, which began at age 68 years in 1964. He was managed at the National Parkinson Foundation but he died in 1973. All three patients were L-dopa responsive although the father had to stop taking this drug because of gastric side effects. The son and mother are still alive. The son is more severely affected by parkinsonism than his mother. The family lived together until the index case went away to college. An older brother also alive and well, remains unaffected. The unaffected brother was the only member of the family who refused to follow the father's rigorous "health food" diet which included large quantities of sunflower seeds. No other family members had Parkinson's disease. The propositus, his mother, and his son were examined by DBC. The index case's Parkinson's disease has been followed by DBC for 13 years.

\section{Family 2}

The index case (male) presented in 1986 at age 33 with postural tremor, rigidity, facial masking and decreased arm swing and Parkinson's disease was diagnosed. His mother developed similar symptoms in 1981 when she was aged 54 years, and again Parkinson's disease was diagnosed. Both subjects were examined by $\mathrm{DBC}$ and both were responsive to levodopa. The index case is the oldest of four children, the rest of whom are reportedly unaffected. With the exception of two years when the index case was in his late teens, the mother and son have lived on the same farm all their lives. The other brother and two sisters left home on leaving school. Their water supply derived from a well.

\section{Family 3}

The index case (female) developed tremor, rigidity and postural instability in 1984 at age 78 years when Parkinson's disease was diagnosed. She is responsive to levodopa. She reported that a brother had a similar tremor, but since he was not examined, he was not included in the analysis. Her son developed a resting tremor, in 1986 at the age of 57 years. This affected the left hand more than the right, with increased tone at the wrists, these symptoms progressing over 6 months. He was diagnosed as having early Parkinson's disease but remains untreated. Both subjects were examined by WRWM. The son lived at home with his mother and maternal uncle until he left school. The index case has two other children who are alive and well and unaffected.

\section{Family 4}

The index case (female) noticed shaking in one leg in 1980, when she was aged 61 years. Subsequently retropulsion, rigidity and bradykinesia developed and Parkinson's disease was diagnosed in 1983. In 1974 her daughter, aged 30 years, noticed stiffness and tremor of the right wrist and a year later Parkinson's disease was diagnosed. Both subjects responded well to treatment with Sinemet; they were examined by Dr. A. Rajput, Saskatoon. The index case's father remains alive and well and unaffected at age 100 . Her mother, also unaffected, died at age 69 . She has two brothers and five sisters who are all well and two unaffected daughters. One son died in infancy aged 8 months. The daughter shared the same environment as her mother until she was aged 18 years. From ages 10-18 years, the index case and her family employed the same water supply as another patient of Dr. Rajput who developed Parkinson's disease when aged 29 years.

\section{Family 5}

The index case (male) was born in 1923. Bradykinesia and tremor started in 1965. In 1981 the diagnosis of Parkinson's disease was confirmed (DBC) and it was noted that his monozygotic twin was not affected. However, his father, born in 1895 , developed tremor, and weakness of his voice in 1957; Parkinson's disease was diagnosed and he was treated with trihexyphenidyl at that time. No environmental difference was ascertained between the twins and their father.

\section{Family 6}

The index case (female) was born in 1920. Some bradykinesia and intermittent tremor began in 1974 and Parkinson's disease was diag- 
nosed the same year. This was confirmed by DBC. The patient responded to L-Dopa. Her monozygotic twin was unaffected, but her younger sister, born in 1924, developed tremor in 1975 and Parkinson's disease was diagnosed in 1976 (DBC). She also responded to levodopa. There was no obvious environmental difference detectable between the twins and their sister.

The common features running through the familial cases of Parkinson's disease reported here are one or more of the following:

(1) The correlation between onset of clinical symptoms and time.

(2) The lack of correlation between onset of symptoms and age.

(3) The lack of correlation between concordance and degree of consanguinity.

From these findings, we infer that the cause of disease in these patients may have been environmental rather than genetic. Alonso et al (1986), ${ }^{3}$ described two families in which two patients developed akinetic rigid Parkinson's disease at a mean age of 19 years compared with their siblings who became parkinsonian at a mean age of 28.5 years and two families in whom the children developed akinetic rigid Parkinson's disease at a mean age of 38.5 years compared with their parents in whom the disease started at a mean age of 62.5 years (mean difference in age of onset between generations 24 years). In the report by Quinn et al (1986), ${ }^{4}$ a patient developed Parkinson's disease at the age 37 years and his father developed the disease at the age 53 years.

In family 5 , it is of interest that a parent developed the disease at approximately the same time as the index case whose monozygotic twin was unaffected. This observation might be construed as evidence that the environmental factor causing this disease may have been quite transient, occurring in a setting where the index case and parent were together without the co-twin. Another point of interest is that the association between child and parent is more frequently maternal than paternal. In general, children tend to share their mother's environment more than their father's.

All our subjects had tremor as an early symptom in the evolution of their illness. Since 70\% of patients with Parkinson's disease have tremor as their initial symptom, it is not surprising that our families presented in this way. As experience increases, there may be some interest in comparing Parkinson's disease characterized by prominent early tremor with the disease presenting as an akinetic-rigid syndrome.

The concept of "anticipation" might be invoked to account for our results. The onset of disease at earlier ages in successive generations has been explained, in some cases, as an artefact deriving from a more intensive search for illness in the young. This is an unsatisfactory interpretation of our findings because the index cases either presented to us for diagnosis and treatment (families $1,2,4$ ), or came from a survey of twins (families 5,6 ). In only one case (family 3 ) did we find a younger patient because of disease initially identified in an older relative.

An important aspect of our findings is the time of exposure to risk factors. Because the children had generally lived separately from their parents for a period corresponding to the age difference in the time of onset (mean 25.2 years), we conclude that the environmental aetiology must predate the appearance of symptoms by at least this amount of time. This inference is in accord with our previous hypothesis that Parkinson's disease might derive from an interaction between subclinical environ- mental damage in early life and normal aging of the central nervous system.'

We had some bias towards studying families with monozygotic twins because of our previous interest in twin concordance. ${ }^{5}$ but this should not detract from the interpretation of our findings. Similarly, the finding of occasional concordance in monozygotic twins ${ }^{6.7}$ does not detract from our conclusion, since identical twins generally share their environment in early life, in addition to their genes. We recognize that case reports of sibship involvement are entirely in keeping with recessive inheritance, particularly where $25 \%$ of the sibship are affected.

There also exist parents and children developing Parkinson's disease at similar ages. ${ }^{\mathbf{8 . 9 . 1 0}} \mathrm{We}$ should emphasize that we are not arguing against the existence of any genetically determined cases of parkinsonism. We are merely reporting evidence that some familial cases are likely to be of environmental origin. Although we have not formally collected observations on all familial cases of Parkinson's disease we have seen several examples similar to those reported here, but not included because of incomplete information. We consider that at least half of the familial clustering which we have observed conforms to the pattern described here. We consider that further evidence should be sought on risk factors preceding parkinsonian symptoms by at least two decades. Other degenerative diseases of the nervous system such as Alzheimer's disease and motor neuron disease should be studied to determine whether any families afford similar evidence for an early environmental cause, although in these disorders genetic subtypes appear to be quite common.

\section{ACKNOWLEDGMENTS}

We wish to thank Dr. R. Eldridge, Dr. A. Rajput, Dr. J. Nutt and Dr. R. Duvoisin for permission to publish details of their patients. This work was supported by the Dystonia Medical Research Foundation and the MRC of Canada. P.S.S. by NIH grant NS 19611

\section{REFERENCES}

1. Calne DB, Eisen A, McGeer E. Spencer P. Alzheimer's Disease, Parkinson's disease and motorneurone disease: Abiotropic interaction between ageing and environment? The Lancet 1986; 2: 1067-1070.

2. Schoenberg BS, Anderson DW. Haerer AF. Racial differentials in the prevalence of Parkinson's disease: A neuroepidemiologic study of a biracial county in rural Mississippi. Neurol 1986: 36 : 841-845.

3. Alonso ME, Otero, D'Regules R, Figueroa. Parkinson's Disease: A genetic study. Can J Neurol Sc 1986; 13: 3: 248-251.

4. Quinn NP, Critchley P, Marsden CD. Young onset Parkinsonism. Neurology 1986; 36:1: 215.

5. Ward CD, Duvoisin RC, Ince SE, Nutt JD, Eldridge R, Calne DB. Parkinson's disease in 65 pairs of twins and in a set of quadruplets. Neurol 1983; 33: 815-824.

6. Koller W, O'Hara R, Nutt J, Young J, Rubino F. Monozygotic twins with Parkinson's disease. Ann Neurol 1986; 19: 402-405.

7. Jankovic J, Reches A. Parkinson's disease in monozygotic twins. Ann Neurol 1986; 19: 405-408.

8. Barbeau A, Roy M. Familial subsets in idiopathic Parkinson's disease. Can J Neurol Sc 1984: 11: 1: 144-150.

9. Zetusky WJ, Jankovic J, Pirozzolo J. The heterogeneity of Parkinson's disease: Clinical and prognostic implications. Neurol 1985;35:4: 522-526.

10. Gudmundsson KR. A clinical survey of Parkinsonism in Iceland. Acta Neurol Scand 1967; 43(33): 1-61,18-23,56-59. 